The new enthusiasm for industrial sociology has tended to obscure the older studies of individual differences. It may now be time to look at these again in the light of better understanding of the social pressures involved.

Examination of status systems in industry is not new. Nevertheless, there is need to know more about the extent to which the use of the special knowledge and ability of the technician or technologist is hindered by the status systems in industry, particularly the caste system dividing management from technical grades. This is in need of overhaul based on sociological understanding.

The work of Simon and his associates in the United States has shown what can come from a rigorous analysis of some aspects of decision taking. There is a point in each organization at which there is someone who has the necessary authority to take a particular decision. Also located in this organization is someone who has the knowledge for the best decision to be taken. The problem is how to get these two points to coincide: How can effective authority coincide with effective knowledge ?
Industrial relations generally means relationship of management to labour. Equally important for the health of any concern is its management/management relations. These may not burst into active conflict, but latent conflict is continuous and may be dangerous. This conflict is neither altogether avoidable nor altogether bad; every time a functional organization is set up a conflict of interest is created. Each functional department tends to seek to maximize what, from the point of view of the organization as a whole, needs to be optimized. For example, a production department will naturally have maximum production as its goal; an inspection departmont will naturally tend to seek maximum quality or minimum errors. From the point of view of the concern as a whole, a compromise between these conflicting aims has to be achieved. Less obvious but equally profound conflicts of aim will occur between the personnel department and the department of the accountent or financial controller. The problem is not how to resolve this conflict but how best to use it and keep it within bounds.

T. H. Hawkins

\title{
TRAINING ENGINEERING GRADUATES
}

$\mathrm{T}$ HE graduate aiming at membership of one of the professional engineering institutions normally undergoes a period of practical training or apprenticeship following the completion of his undergraduate course.

Some three years ago the Institution of Electrical Engineers issued a report entitled "The Training of Graduates" in which the purposes of practical training for graduates were outlined and recommendations for the structure of training courses were made. This report, revised and modified, has now been re-issued*.

The general pattern of training recommended does not differ in its essential features from that described in the earlier report. Training should occupy two years and should comprise basic workshop training, general mechanical and electrical training and what is termed directed objective training. It is emphasized that each phase of the training course should be carefully plenned and supervised and that the graduate in his practical training should continue to experience something of the intellectual stimulus and of the urge to intensive individual effort which are inherent in academic studies.

- Institution of Electrical Engineers. The Training of Graduates : a Report of the Joint Committee on Practical Training in the Elec trical Engineering Industry. Pp. 34. (London : Institution of Electrical Engineers, 1960.) $2 s$.
Separate sections of the report deal with schemes of training conducted in a works making heavy electrical plant, a factory for light-current equipment and in an operating organization, such as an electricity supply undertaking or a telecommunication service.

While the majority of electrical engineers study, as undergraduates, electrical engineering, a substantial proportion read physics and a few mathematics. The special needs and interests of such graduates in physics and mathematics are met by a scheme of training based on the laboratory but providing for some direct contact with manufacture and development.

There is one important new feature in the recommendations. This is the recognition of training through experience in a staff appointment as an alternative to the traditional form of graduate apprenticeship. This envisages the graduate being engaged as a member of the staff of a professional engineer who will directly supervise his training. The training course will not then conform to any standard pattern, but will comprise the acquiring of experience on a series of projects. These will be so chosen as to provide in the aggregate a range of experience equivalent to that provided by the normal graduate apprenticeship. Great stress is laid on the personal responsibility accepted by the engineer who undertakes to provide this type of training.

\section{POLIOMYELITIS}

CINCE the last World Health Organization special$S$ ist Committee on Poliomyelitis met in 1957 not only have inactivated poliovirus vaccines come into widespread use but also live attenuated vaccines have been submitted to intensive study and, in some countries, have already been employed on a scale that could scarcely have been envisaged three years ago. These developments and the problems they raise are fully reviewed in the third report of the
Committee (Expert Committee on Poliomyelitis, Third Report. World Health Organization: Technical Report Series, 1960, No. 203 ; 53 pages. Price : 3s. 6d., 0.60 dollars, Sw. Fr. 2. Also available in Spanish and French).

In most countries where inactivated vaccines have been widely used the protection obtained has been of the order expected on the basis of controlled field trials. Manufacturing and testing problems appear to 